dressings applied many years ago as affected and brought out by continuous dressings of nitrogenous manures is another significant fact; while the evanescent effect of nitrates applied as salts contrasts unfavourably with the continued effects of nitrogenous matter in organic combination with carbon. Prof. Fream's book is a substantial addition to agricultural literature, and it is satisfactory to find that the editing of such important results has been carried out, with the "kind and ready " assistance of Sir John Lawes and Dr. Gilbert, by one who brings sound scientific attainments to bear upon a stupendous number of observations made during a series of forty years. There is room for a second, if not a third volume, as the experiments upon the cultivation of the root crops, the leguminous crops, and the elaborate researches made at Rothamsted upon the fattening of animals, are not touched in this first instalment.

\section{THE JAPANESE VOLCANIC ERUPTION.}

THE Times of Tuesday contains a long letter from its Japan Correspondent describing the scene of the recent volcanic explosion in the Bandai-san region in Northern Japan. This is the first account by a foreign eye-witness that has reached the outside world. The writer appears to have started immediately from Tokio for the scene of the disaster, where he spent four days going carefully over the ground, examining the phenomena connected with the outburst, and hearing the stories of the survivors. The communication which is the result of these investigations, and which was evidently written while the powerful impression left by the scene of awful desolation was still fresh in the writer's mind, is probably one of the most graphic and detailed accounts of the immediate results of a stupendous volcanic explosion that has ever been published. Bandai-san is a mountain about 5800 feet high, and has shown no sign of activity for about eleven hundred years. On its north-eastern flank was a subordinate peak known as Little Bandai-san, which rose directly above a group of three solfataras.

At about 8 .o'clock on the morning of July $\mathrm{I}_{5}$ (here, as throughout almost the whole of this article, we quote the Times Correspondent), almost in the twinkling of an eye, Little Bandai-san was blown into the air and wiped out of the map of Japan. A few minutes later its débris had buried or devastated an area about half the size of London. A dozen or more of upland hamlets had been overwhelmed in the earthen deluge, or wrecked by other phenomena attending the outburst. Several hundreds of people had met with sudden and terrible death. Scores of others had been injured; and the long roll of disaster included the destruction of horses and cattle, damming up of rivers, and laying waste of large tracts of rice-land and mulberry-groves. A small party was organized in Tokio to visit the scene. As the travellers approached the mountain, they were told that twenty miles in a straight line from Bandai-san no noise or earthquake was experienced on the 15 th, but mist and gloom prevailed for about seven hours, the result of a shower of impalpable blue-gray ash, which fell to a depth of half an inch, and sorely puzzled the inhabitants. An ascent of about 3000 feet was made to the back of the newly-formed crater, so as to obtain a clear view of it and of the country which had been overwhelmed. Orily on nearing the end of the ascent were they again brought face to face with signs of the explosion. Here, besides the rain of fine gray ashen mud which had fallen on and still covered the ground and all vegetation, they came upon a number of freshly-opened its, evidently in some way the work of the volcano. Ascending the last steep rise to the ridge behind Little Bandai-san, signs of the great disaster grew in number and intensity. "Foetid vapours swept over us, emanating from evil-looking pools. Great trees torn up by their roots lay all around; and the whole face of the mountain wore the look of having been withered by some fierce and baleful blast. A few minutes further and we had gained the crest of the narrow ridge, and now, for the first time, looked forth upon the sight we had come to see. I hardly know which to pronounce the more astonishing, the prospect that now opened before our eyes or the suddenness with which it burst upon us. To the former, perhaps, no more fitting phrase can be applied than that of absolute, unredeemed desolation-so intense, so sad, and so bewildering, that I despair of describing it adequately in detail. On our right, a little above us, rose the in-curved rear wall of what, eight days before, had been Sho-Bandai-san, a ragged, almost sheer, cliff, falling, with scarce a break, to a depth of fully 600 feet. In front of this cliff everything had been blown away and scattered over the face of the country before it in a roughly fanshaped deposit of for the most part unknown depth-deep enough, however, to erase every landmark and conceal every feature of the deluged area. At the foot of the cliff, clouds of suffocating steam rose ceaselessly and angrily, and with loud roaring, from two great fissures in the crater bed, and now and then assailed us with their hellish odour. To our eyes, the base denuded by the explosion seemed to cover a space of between three and four square miles. This, however, can only be rough conjecture. Equally vague must be all present attempts to determine the volume of the disrupted matter. Yet, if we assume, as a very moderate calculation, that the mean depth of the débris covering the buried area of thirty square miles is not less than $1 ;$ feet, we find that the work achieved by this last great mine of Nature's firing was the upheaval and wide distribution of no fewer than $700,000,000$ tons of earth, rocks, and other ponderous material. The real figure is probably very much greater."

The desolation beyond the crater, and the mighty mass thrown out by the volcano which covered the earth were almost incredible. "Down the slopes of Bandai-san, across the valley of the Nakasegawa, choking up the river, and stretching beyond it to the foot-hills five or six miles away, spread a vast billowy sheet of ash-covered earth or mud obliterating every foot of the erstwhile smiling landscape. Here and there its surface was dotted or streaked with water. Elsewhere the eye rested on huge disordered heaps of rocky débris, in the distance resembling nothing so much as the giant concrete block substructure of some modern breakwater. It was curious to see on the farther side the sharp line of demarcation between the brown sea of mud and the green forests on which it had encroached; or, again, the lakes formed in every tributary glen of the Nakasegawa by the massive dams so suddenly raised against the passage of their stream waters. One lake was conspicuous among the rest. It was there that the Nakasegawa itself had been arrested at its issue from a narrow pass by a monster barrier of disrupted matter thrown right across its course. Neither living thing nor any sign of life could be descried over the whole expanse. All was dismally silent and solitary. Beneath it, however, lay half a score of hamlets, and hundreds of corpses of men, women, and children, who had been overtaken by swift and painful deaths."

Near by two houses, built for the accommodation of visitors to the hot springs were overwhelmed, and a little lower down two spa-hamlets were absolutely buried in mud. From various indications, especially a comparison of the places destroy'ed with those saved, it appears that the disruptive force must, in the main, have been directed outwards from the hill-face at a considerable inclination to the vertical. On no other hypothesis is it possible to account for some of the most startling phenomena, for the great distances reached by the waves of ejectamenta, and for the incredibly brief intervals that 
elapsed between the short-lived explosion and the submersion of large tracts many miles away from the crater. It must not, however, be supposed that the havoc wrought by the volcano's fury was limited to the fall of disrupted matter, or to the area covered by it. Besides the rain of scalding earth and mud, heated rocks and stones, sand, and hot softly-falling ashes, there were the awful shocks of the explosion, accompanied by winds or whirlwinds, which every survivor describes as of intense and extraordinary vehemence. Nowhere, of course, were the effects of these concomitants more fierce than on the heights of Bandai-san. The forests on the unburied slopes above and near the crater presented a weird spectacle. In these hardly a stick was left standing. As if some giant reaper had mown down whole acres with a sweep of his sickle, the trees lay literally in hundreds on the ground, all felled in a direction away from the crater, stripped of branches, leaves, and even of their bark, and twisted into the most grostesque contortions.

One day was given to exploring the buried area at its lower levels in the valley of the Nakasegawa, and also the outskirts of the volcanic deluge. At one place, a secondary earth-wave, issuing from the crater by a lateral gap, had rushed swiftly down the mountain-side, burying a large party of grass-cutters and horses, and reaching, but only half destroying, the little hamlet of Mine. Its energy seems to have exactly spent at this point. It was strange to see the great wall of earth and stones, with its vertical fisce some 7 or 8 feet high, brought up allstanding, as it were, by a frail farm outbuilding. A yet stranger sight was it to see the enormous masses of rock that were strewn about on the surface of the neighbouring field of mud. One of them, which was measured, weighed at least 200 tons. Higher up, on the far side of the river, a couple of large villages, in which, though not reached by any mud-stream, not a house was whole, many had been levelled to the ground; others were tottering on the verge of destruction; and of the rest, all were cracked, mutilated, unroofed, twisted, tilted up, or otherwise injure 1 or partially wrecked. A sccne of more ruthless and utter desolation could hardly be conceived. Beyond this, the route entered upon the great earth-field visible from the heights of Bandai-san. Nothing could convey a more vivid idea of the destructive forces that were let loose upon that doomed region than a sight of the wild chaos of earth, rock, and mud which now reigns over its surface. The whole effect in some places is much as if a raging sea of those materials, on a gigantic scale, had been suddenly congealed and made to stand still. At one spot there is a long mud precipice, said by some observers to be fully 200 feet high.

Although the little village of Nagasaka was comparatively uninjured, nearly all its able-bodied inhabitants lost their lives in a manner which shows the extraordinary speed with which the mud-stream flowed. When -Little Bandai-san blew up, and hot ashes and sand began to fall, the young and strong fled panic-stricken across the fields, making for the opposite hills by patbs well known to all. A minute later came a thick darkness, as of midnight. Blinded by this, and dazed by the falling débris and other horrors of the scene, their steps, probably also their senses, failed them. And before the light returned every soul was caught by a swift bore of soft mud, which, rushing down the valley bed, overwhelmed them in a fate more horrible and not less sudden than that of Pharaoh and his host. None escaped save those who stayed at home-mostly the old and very young.

From the stories told by the survivors, as well as from his own observations, the writer sketches the following sequence of events connected with the outburst :-

It seems clear from every account that one of the most terrible features of the catastrophe must have been its appalling suddenness. Though there had been, it is said, slight shocks of earthquake for a couple of days before, and, according to some witnesses, strange subterranean rumblings and suspicious variations in the temperature and volume of the hot springs, these caused no grave alarm. Nothing worthy to be called a serious warning occurred until about 7.30 a.m. on the 15 th. Then came a violent earthquake, followed a quarter of an hour later by a second, yet more intense. Ten minutes after there ensued throes of such terrible severity that the ground heaved and fell, people were thrown down, and houses demolished or wrecked. To all it seemed that their last hour had come. Instantly upon this arose a fearful noise, described by some as like that of a hundred thunders, by others as the most unearthly sound that ever startled the ears of men. Little Bandai-san was seen to be lifted bodily into the air and spread abroad, and after it leaped forth tongues of flame and dense dark clouds of vapour of ejectamcnta. Of the ensuing phenomena it is hard to gain any clear idea from the tales of the distracted survivors. Apparently, however, a quick succession of reports, accompanied by violent earth-throes and winds of hurricane force, lasted for about a minute. Then began the shower of ashes, dust, hot water, and leaves. The light quickly faded as the exploded matter spread over the firmament, so that day was soon changed into night, and did not return for a space of several minutes. Meanwhile, the avalanches of earth and mud must have already done much of their deadly work. The interval between the explosion and the arrival of the mud-torrent which swept past that hamlet cannot have been more than from ten to fifteen minutes. Before the light was restored, all the flower of the village had been swallowed up. How that long journey of some ten miles from the crater had been performed by the mud at such an astonishing speed it is impossible to say. There is evidence that in places the earth-flow lasted for about an hour. But in the above we have the clearest proof that some at least of the destroying matter was hurled over the country at railroad speed, even after being deflected through wide angles from its original line of motion.

We may, perhaps, hope to learn something hereafter that will throw a clear light on the immediate cause of the explosion (the agent, it cannot be doubted, was steam), on the approximate volume of the projected matter, on the partiality of the effects, and on the many and most be wildering mysteries connected with the propagation and distribution of the earth-waves, rocks, \&c. Meanwhile we have before us the fact that a massive mountain peak has been blown to bits by an explosion within its bowels powerful enough to toss many hundred millions of tons of material high into the air, and to change the face of nature over an area of some thirty square miles. While whole forests were levelled by the shock, the disrupted matter dammed up rivers, deluged and drowned the land and crops, and buried a dozen hamlets. Earthquakes and coups de vent added their quota to the work of destruction. Nearly 600 people perished by horrible deaths in their mountain homes and valleys. Four times that number have been reduced to destitution or dire poverty. With one possible exception, it is the gravest disaster of its class that has happened, even in that land of volcanoes since the famous eruption of Asamayama in 1783 , and it cannot but be ranked among the most startling volcanic explosions of which history has any record.

It is interesting to know that experts are already at work investigating some of the problems here sketched out by the Times Correspondent, and happily Japan is well provided with experts in the science of seismology, at their head being Prof. Milne, the leading seismologist of the day. Seeing also the countenance given to the study of these phenomena by the Japanese Government, it may be anticipated that no volcanic eruption of modern times will have been so carefully and scientifically investigated as this of Bandai-san, as none has been so graphically and eloquently described. 